Article

\title{
The Association between Milk and Dairy Products Consumption and Nutrient Intake Adequacy among Japanese Adults: Analysis of the 2016 National Health and Nutrition Survey
}

\author{
Aki Saito, Emiko Okada ${ }^{\mathbb{D}}$, Iori Tarui ${ }^{\mathbb{D}}$, Mai Matsumoto and Hidemi Takimoto * \\ Department of Nutritional Epidemiology and Shokuiku, National Institutes of Biomedical Innovation, \\ Health and Nutrition, 1-23-1 Toyama Shinjuku-ku, Tokyo 162-8636, Japan; saitoa@nibiohn.go.jp (A.S.); \\ okadae@nibiohn.go.jp (E.O.); nhtun@nibiohn.go.jp (I.T.); m-matsumoto@nibiohn.go.jp (M.M.) \\ * Correspondence: thidemi@nibiohn.go.jp
}

Received: 23 August 2019; Accepted: 26 September 2019; Published: 3 October 2019

\begin{abstract}
Consumption of dairy products in the usual diet may be important for improving the overall quality of dietary intake. This study aimed to assess the difference in nutrient intake adequacy according to the intake of dairy products based on a 1-day weighed dietary record of Japanese adults from the 2016 National Health and Nutrition Survey. Nutritional adequacy was determined based on the Dietary Reference Intakes for Japanese 2015, with 2 goals: Tentative dietary goals (DG) for preventing lifestyle-related diseases, and the estimated average requirement (EAR). According to the dairy products consumption, participants were categorized into three groups (milk, other dairy product, or non-dairy), and the total number of those not meeting DG and EAR was compared. Non-dairy consumers were less likely to meet both DG and EAR compared to dairy consumers. Dairy consumers were more likely to exceed the DG for saturated fat than non-dairy consumers. Japanese adult dairy consumers were more likely to have adequate nutritional intake than non-dairy consumers, especially for calcium. We also observed a higher saturated fat intake in dairy consumers, which might be due to a certain dietary pattern in this group. Further investigation is needed to determine dairy intake and its influence on dietary quality among the Japanese population.
\end{abstract}

Keywords: National Health and Nutrition Survey (NHNS), nutritional adequacy; milk; dairy; Japan

\section{Introduction}

Dairy products, such as milk, cheese, and yoghurt provide an abundant source of nutrients, including protein, vitamins, and minerals, and their nutritional value has been well recognised [1-3]. Their beneficial roles have been examined in association with a variety of chronic diseases, including hypertension, metabolic syndrome, type 2 diabetes, and cardiovascular diseases, as well as in maintaining bone health [3-9].

Several studies have shown that the intake of dairy products may improve nutrient intake [10-16]. For example, in a study of Australian children, drinking milk was related to higher intake of micronutrients [10]. Other studies targeting children also reported the positive influence of dairy consumption on the intake of nutrients [11-13]. In an Irish study, it also has been suggested that dairy products contribute to the intake of micronutrients such as calcium and retinol [14], while another study has reported that yogurt intake was associated with better diet quality in American adults [15]. Moreover, some researchers have indicated that it is challenging to achieve adequate intake of essential nutrients, such as calcium, potassium, and magnesium, without dairy products in the diet [17]. Studies on dairy intake in relation to nutritional quality have been conducted among Western populations. On 
the other hand, few comparable studies in Asian countries have been reported. A traditional, typical Japanese diet is a combination of rice, soybean products, fish, seaweed, and green tea [18], which is different from Western countries. The intake of dairy product (milk, cheese, yogurt, and cream) in Japan has been reported to be approximately $110 \mathrm{~g} /$ day/capita, including only $63 \mathrm{~g} /$ day/capita of milk [18], which is relatively low compared with Western countries [19]. Thus, the influence of the amount/pattern of dairy product consumption on other dietary intakes may differ between Asian and Western populations. Hence, determining the influence of dairy products on adequate nutrient intake among Japanese people using a nationally representative sample is important to Asian populations.

The objective of the present study was to compare nutrient intake adequacy, as well as other food intake, between Japanese adult non-dairy-product consumers, dairy product consumers, and milk consumers, using the 1-day dietary record in the 2016 National Health and Nutrition Survey in Japan (NHNS).

\section{Materials and Methods}

\subsection{Data Source and Study Population}

This study was based on data from the 2016 NHNS. The NHNS is a series of nationally representative, cross-sectional nutrition surveys conducted by local public health centres under the supervision of the Ministry of Health, Labour, and Welfare. The NHNS collects information on health status, food and nutrient intake, and lifestyle of Japanese civilians using a 2-stage cluster sampling scheme. Detailed descriptions of the survey procedures have previously been published [18]. In brief, participants are the individuals aged 1 year or older in the households in selected 475 census units. The survey was conducted from 1 October to 30 November 2016. A total of 10,745 of 24,187 eligible households (44.4\%) agreed to participate in the survey. The current study was limited to data collected from 21,851 adults (20 years old and older) who completed information on dietary intake out of 26,225 adult participants. Lactating or pregnant women were excluded from the present analysis since they were presumably not following their usual diet $(n=245)$, for example, due to fear of excess weight gain [20]. Additionally, a previous Japanese study showed that lactating women consumed more dairy products than non-lactating women [21]. The final analytic sample comprised 21,606 participants (9987 men and 11,619 women). This survey was conducted according to the guidelines laid down in the Declaration of Helsinki, and verbal informed consent was obtained from each participant. Under the Statics Act, the Ministry of Health, Labour, and Welfare anonymised individual-level data collected from the NHNS and provided the first author with the datasets for this study. In accordance with the Ethical Guidelines of Epidemiological Research established by the Ministry of Education, Culture, Sports, Science, and Technology, as well as the Ministry of Health, Labour, and Welfare, institutional review board approval was not required for this analysis. As this study is a secondary analysis of the 2016 NHNS, we did not perform a sample size calculation.

\subsection{Dietary Assessment}

Dietary intake data were collected using a 1-day semi-weighed household dietary record. Participants recorded the food consumption of their household for a usual day, excluding trip or festivity days. During the orientation session before the survey, trained fieldworkers (mainly registered dietitians) gave instructions to participants about the survey purpose and how to complete the dietary record. The main record-keepers in a household (members who are usually responsible for preparing meals) were instructed to weigh all foods and beverages consumed by household members and record their names and weights on open-ended recording forms, including the amounts of food waste and leftovers. The main record-keepers were also asked to record the approximate proportions of food consumed by each household member when members shared foods from the same dish, so that the dietary intake of each individual could be calculated. When weighing was not possible, the main-record keepers were asked to record as much information as possible, including portion size 
consumed or quantity of foods (using household measures) and details of any leftovers. Trained fieldworkers visited each household and checked the completeness of recording forms and, if necessary, confirmed portion sizes using commercially available food models or food booklets, and corrected any missing and/or illogical information. In accordance with the survey manual of the NHNS, the trained fieldworkers converted these estimates of portion sizes or quantities of food into food weights and coded each food item according to the NHNS food number list. These food number lists were based on the Standard Tables of Food Composition in Japan [22]. When the reporting of the ingredients of mixed dishes was uncertain, such as when eating out in restaurants, common food compositions were allocated to the mixed dish according to typical Japanese recipes [21]. The collected recording forms and converted data were further checked at the local public health centre, and trained fieldworkers inputted dietary intake data using software specifically developed for the NHNS. These data were then compiled by trained investigators at the central office to create a whole dietary dataset. Nutrient intake from dietary supplements or nutrient-fortified food were not assessed because of the lack of reliable databases in Japan.

This household-based dietary record method has been compared to individual dietary records in Japanese participants [23]. Intakes in 32 female dietetic students, as recorded by the students themselves, were compared against the 1-day household dietary record completed by their mothers. Pearson correlation coefficients were 0.90 for energy, 0.89 for protein, 0.91 for total fat, and 0.90 for carbohydrate. Additionally, Murakami et al. reported that the energy intake estimates using NHNS were 0.98 times that of the estimated energy requirement (EER) for adults aged 20 years and older [24].

To enable the comparison between the nutrient intake and the Japanese dietary reference intake (DRI) values, we adjusted the reported dietary intake based on the assumption that the energy intake of each participant was the same as his/her EER using the following calculation: dietary intake $($ unit/day $)=$ reported dietary intake $($ unit/day $) /$ reported energy intake $(\mathrm{kcal} /$ day $) \times$ EER $(\mathrm{kcal} /$ day $)$. Since we could not obtain data on each participant's physical activity level, the EER value was determined assuming that each individual's physical activity level was at the "second" (middle) level in the Japanese DRIs [25]. This level corresponds to a moderate physical activity status where individuals spend most of the day sedentary at work, but including movement and housework, such as commuting and shopping, as well as sports with light intensity [25]. For protein, total fat, saturated fat, and carbohydrate intake, a percentage of the daily energy intake was calculated using the crude values and used for comparison with the DRI values.

\subsection{Other Variables}

Body height (to the nearest $0.1 \mathrm{~cm}$ ) and weight (to the nearest $0.1 \mathrm{~kg}$ ) were measured for approximately $90 \%$ of the participants by trained field workers using standardised procedures. For the remaining participants, height and weight were measured either by other household members at home or were self-reported. Body mass index (BMI) was calculated as weight $(\mathrm{kg})$ divided by height (m) squared. Using a self-administered questionnaire, smoking status and alcohol drinking habits during the preceding month were assessed.

\subsection{Determination of Nutritional Intake Adequacy}

Adequacy of each nutrient intake was determined by comparing nutrient levels with each dietary reference value according to the Japanese DRIs, using a cut-point method as previously reported [26-28]. In the Japanese DRIs [25], different reference values are established according to their purpose. The estimated average requirement (EAR) is an intake value estimated as having a $50 \%$ risk of insufficiency and is set to avoid insufficient intake. The tentative goal for preventing lifestyle-related disease (DG) is either an upper or lower limit of the intake value set to prevent lifestyle-related disease. An intake level below the EAR was considered as "not meeting" using the cut-point method for 14 nutrients, which were protein, vitamin A expressed as retinol equivalents, thiamine, riboflavin, niacin expressed as niacin equivalent, vitamin B-6, vitamin B-12, folate, vitamin C, calcium, magnesium, iron (except for women 
aged 20-49 years), zinc, and copper. Retinol equivalents were calculated as follows: $1 \mu \mathrm{gRE}=$ retinol $(\mu \mathrm{g})+$ beta-carotene $(\mu \mathrm{g}) \times 1 / 12+$ alpha-carotene $(\mu \mathrm{g}) \times 1 / 24+$ beta-cryptoxantin $(\mu \mathrm{g}) \times 1 / 24+$ other provitamin A carotenoides $(\mu \mathrm{g}) \times 1 / 24$. Niacin equivalent was calculated as follows: niacin $(\mathrm{mg})+$ protein $(\mathrm{mg}) / 6000$. For iron, the cut-point method is not appropriate for menstruating women $[29,30]$. Therefore, we applied the value $<9.3 \mathrm{mg} /$ day as shown by the World Health Organization (WHO) (bioavailability of iron as $15 \%$, probability of inadequacy as 50\%) [31] for women 20-49 years old. Although the EAR was set for biotin, chromium, molybdenum, selenium, and iodine in the Japanese DRIs, these nutrients were excluded from this study because food composition tables in Japan provide incomplete data for these nutrients. An intake level falling outside the range of DG values was considered as not meeting the standard for 7 nutrients of the DG, which were percent energy from protein, total fat, saturated fat, carbohydrates, total dietary fibre, sodium, and potassium. Sodium was calculated as salt-equivalent $($ salt $(\mathrm{g})=58.5 / 23 \times$ sodium $(\mathrm{g})$ ).

\subsection{Statistical Analysis}

All statistical analyses were performed with SAS statistical software, version 9.4 (SAS Institute Inc., Cary, NC, USA). All reported $p$ values were two-tailed, with a $p$ value $<0.05$ considered statistically significant. All statistical analyses were performed separately by sex.

The participants were categorized into 3 groups according to their intake of milk and dairy products: Those who reported consuming liquid milk (cow milk: full-fat, low-fat, non-fat milk, and flavoured milk) with or without other dairy products (whole milk powder, cream, yoghurt, natural cheese, and processed cheese) were categorized as "milk consumers"; those who reported consuming other dairy products but not milk were categorized as "other dairy consumers"; and those who did not consume any milk nor dairy products were categorized as "non-dairy consumers". Table 1 shows the definition of milk and dairy products in this study. The mean of age and BMI (continuous variables) of the 3 groups (independent variable with fixed effect) was compared using an analysis of variance (ANOVA) with SAS PROC ANOVA command. The chi-square test was used to compare proportions of age category, BMI category, residential block, current smokers, and habitual drinkers (categorical variables) using the PROC FREQ command. We also examined the intake of different groups of food based on the NHNS food group categories [18], presented by intake weight (grams) per energy intake of $1000 \mathrm{kcal}$, across the participant groups, using the Kruskal-Wallis test (PROC NPAR1WAY).

Table 1. Definition of milk and dairy products in the study.

\begin{tabular}{|c|c|c|}
\hline Food Group & Included Foods & $\begin{array}{l}\text { Food Item Number in the } \\
\text { Standard Tables of Food } \\
\text { Composition in Japan [20] }\end{array}$ \\
\hline Milk & $\begin{array}{l}\text { Ordinary milk, high fat milk, low fat milk, } \\
\text { skimmed milk, milk beverages }\end{array}$ & $13001-13010$ \\
\hline Other dairy products & Milk powder, cream, yogurt, cheese & $13012-13028,13031-13041$ \\
\hline
\end{tabular}

The median and interquartile range (IQR) of energy and nutrient intake were calculated for each group and significant differences across the groups were assessed using the Kruskal-Wallis test and subsequent post hoc analyses (Dwass, Steek, and Critchlow-Fligner method). The percentage of participants whose intake was below the EAR or outside the range of the DG was estimated. The Cochran-Mantel-Haenszel test was used to examine the difference in the preference of not meeting DRIs between the groups adjusting for age categories (PROC FREQ). To examine the overall nutritional adequacy of each participant, the number of nutrients with EAR and DG was counted, respectively. The number of nutrients with not meeting DRIs was 0-14 for the EAR and 0-7 for the DG. The difference in the numbers of nutrients with not meeting DRIs between the groups was assessed using analysis of co-variance (ANCOVA) adjusting for the age categories (PROC GLM). 


\section{Results}

The basic characteristics of the participants according to dairy product consumption are shown in Table 2. The mean ages were 57.2 years (standard deviation (SD), 17.4) old for men and 58.8 years old for women (SD, 17.5). The mean milk intake was $60.9 \mathrm{~g} /$ day (SD, 109.6) and $69.5 \mathrm{~g} /$ day $(\mathrm{SD}, 107.2)$ and that of other dairy products was $32.8 \mathrm{~g} /$ day $(\mathrm{SD}, 60.5)$ and $43.7 \mathrm{~g} /$ day $(\mathrm{SD}, 64.8)$ in men and women, respectively. A total of 3990 men (40.0\%) and 5345 women (46.0\%) reported consuming liquid milk and 2364 men $(23.7 \%)$ and 3102 women $(26.7 \%)$ reported consuming other dairy products on the dietary recording day, while the others did not consume dairy products. There were significant differences in the mean age, BMI, proportions of each BMI category, residential block, and the number of current smokers and habitual alcohol drinkers across the groups in both men and women $(p<0.05)$. 
Table 2. Basic characteristics of 9987 men and 11,619 women according to dairy intake status 1,2

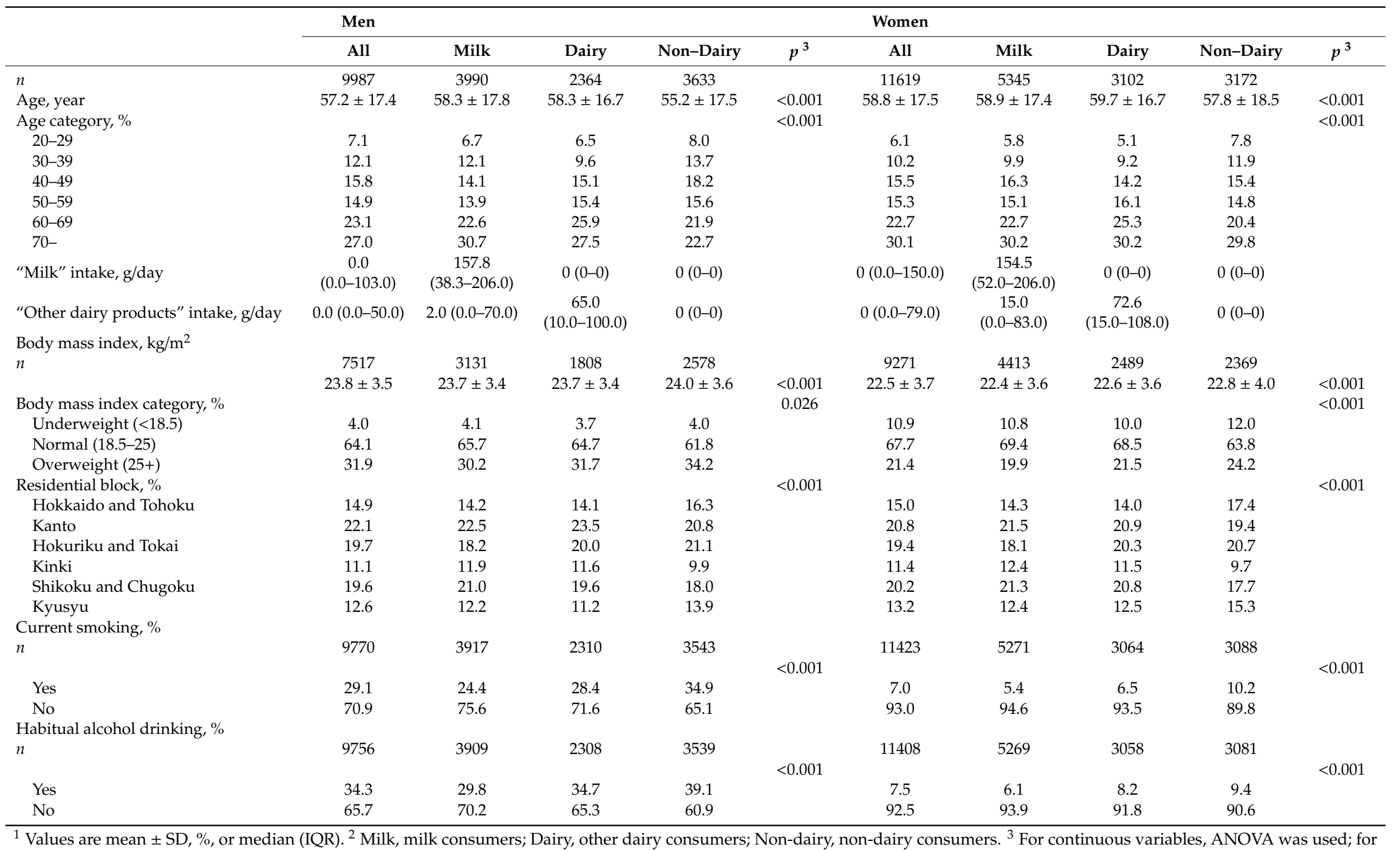

categorical variables, a chi-square test was used to test differences across the groups. 
Table 3 shows food group intake across the dairy consumption status. Men and women showed similar differences in food intakes across the groups. In both sexes, the intake of "grains", "sugars", "sesame and nuts", "vegetables", "fruits", "mushrooms", "fish and shellfish", "oils", "confectionaries", "beverages", and "seasonings" were significantly different $(p<0.05$ for each food group). In men, "pulses" and "egg" intake were also significantly different among the groups $(p=0.037, p=0.002$, respectively), while "seaweeds" intake was significantly different among the groups in women $(p=0.029)$. Non-dairy consumers had the highest intakes of "grains" and "seasonings", while they also had the lowest intakes of "sugars", "sesame and nuts", "fruits", "mushrooms", "oils", and "confectionaries" $(p<0.05)$. Among men, non-dairy consumers also had the lowest intake of "vegetables" $(p<0.05)$. In milk consumers, the intake of the "oil" food group was higher than in other dairy consumers and non-dairy consumers in both men and women, while the intake of "fish and shellfish" was lower than in the other two groups $(p<0.05)$. Other dairy consumers had a higher intake of "beverages" than the other two groups $(p<0.05)$.

Tables 4 and 5 show the energy and nutrient intake and prevalence of not meeting DG and EAR across the groups in men and women, respectively. Significant differences in mean energy and nutrient intake values between the groups were observed for all nutrients in men and women $(p<0.05)$, except for vitamin B12 in men. In men, carbohydrate and sodium intakes were higher among non-dairy consumers, while all the other nutrient intakes, except for niacin and iron, were higher in milk and/or other dairy consumers. In women, carbohydrate, sodium, and copper intakes were higher among non-dairy consumers, while dietary fibre, folate, and vitamin $C$ intakes were the highest in other dairy consumers $(p<0.05)$. Iron intake was lower among milk consumers compared to other groups $(p<0.05)$. Intake of all other nutrients, except for niacin, in milk and/or other dairy consumers compared to non-dairy consumers was higher in women. Among men, the prevalence of not meeting DRIs was only significantly higher for saturated fat in milk consumers and dairy consumers than in non-dairy consumers. The prevalence of not meeting DRIs for all remaining nutrients, except for niacin and copper, was significantly higher among non-dairy consumers than other groups $(p<0.05)$. Among women, saturated fat was the only nutrient that showed a higher prevalence of not meeting DRIs in milk or other dairy consumers than in non-dairy consumers $(p<0.001)$. The prevalence of not meeting DRIs for the other nutrients, except for total fat, dietary fibre and copper, was higher in non-dairy consumers $(p<0.05)$.

The mean numbers of nutrients with not meeting DG and EAR are shown in Table 6. Among men, the mean number of nutrients with not meeting DG was 3.8 for milk consumers, 3.8 for other dairy consumers, and 4.0 for non-dairy consumers. For not meeting EAR, the mean number was 3.3 for milk consumers, 3.9 for other dairy consumers, and 4.7 for non-dairy consumers. After age-adjustment, non-dairy consumers had a significantly higher number of nutrients with not meeting DG and EAR than other groups $(p<0.001)$. Among women, the mean number of nutrients with not meeting DG also showed a significant difference across the groups, with the numbers of nutrients calculated at 3.8 in the milk consumers, 3.7 for other dairy consumers, and 3.9 for non-dairy consumers $(p=0.02)$. The number of nutrients with not meeting EAR was 3.3, 3.9, and 4.7 in milk consumers, other dairy consumers, and non-dairy consumers, respectively $(p<0.001)$. 
Table 3. Intakes of selected food groups (g/1000kcal) among 9987 men and 11,619 women according to dairy intake status ${ }^{1,2}$

\begin{tabular}{|c|c|c|c|c|c|c|}
\hline Sex & Food Groups (g/1000kcal) & All & Milk & Dairy & Non-Dairy & $p^{3}$ \\
\hline \multicolumn{7}{|l|}{ Men } \\
\hline & Grains & $240.6(192.3-293.2)$ & $223.3(179.3-270.9)$ & $232.4(188.2-283.8)$ & $267.2(214.9-319.7)$ & $<0.001$ \\
\hline & Potatoes & $16.9(0.0-41.2)$ & $18.0(0.0-40.9)$ & $16.3(0.0-40.9)$ & $15.3(0.0-41.5)$ & 0.09 \\
\hline & Sugars & $2.0(0.2-4.6)$ & $2.3(0.5-4.9)$ & $2.4(0.5-5.1)$ & $1.5(0.0-3.9)$ & $<0.001$ \\
\hline & Pulses & $21.0(0.0-48.0)$ & $21.0(1.7-45.7)$ & $22.7(1.4-49.0)$ & $19.8(0.0-50.1)$ & 0.037 \\
\hline & Sesame and nuts & $0.0(0.0-0.4)$ & $0.0(0.0-0.6)$ & $0.0(0.0-0.5)$ & $0.0(0.0-0.0)$ & $<0.001$ \\
\hline & Vegetables & $127.1(81.2-184.1)$ & $130.0(86.8-184.8)$ & $131.9(82.9-189.2)$ & $120.3(73.7-179.2)$ & $<0.001$ \\
\hline & Fruits & $16.0(0.0-71.1)$ & $33.3(0.0-80.8)$ & $32.7(0.0-79.8)$ & $0.0(0.0-48.6)$ & $<0.001$ \\
\hline & Mushrooms & $1.2(0.0-12.1)$ & $2.2(0.0-12.2)$ & $2.3(0.0-13.3)$ & $0.0(0.0-11.2)$ & $<0.001$ \\
\hline & Seaweeds & $1.1(0.0-7.3)$ & $1.1(0.0-7.5)$ & $1.1(0.0-7.6)$ & $1.0(0.0-7.0)$ & 0.08 \\
\hline & Fish and shellfish & $33.0(7.1-58.7)$ & $30.5(6.9-54.3)$ & 34.5 (7.9-61.5) & $34.7(7.0-62.9)$ & $<0.001$ \\
\hline & Meat and poultry & $44.9(22.3-70.6)$ & $44.4(23.9-68.4)$ & $44.8(21.1-68.2)$ & $46.0(20.8-75.2)$ & 0.10 \\
\hline & Eggs & $17.4(1.5-29.4)$ & $17.9(2.9-28.9)$ & $17.8(1.3-29.6)$ & $16.2(0.0-30.1)$ & 0.002 \\
\hline & Oils & $4.6(2.0-7.9)$ & $4.9(2.4-8.1)$ & $4.6(2.0-7.8)$ & $4.3(1.6-7.7)$ & $<0.001$ \\
\hline & Confectionaries & $0.0(0.0-11.2)$ & $0.0(0.0-14.7)$ & $0.0(0.0-13.3)$ & $0.0(0.0-3.3)$ & $<0.001$ \\
\hline & Beverages & $321.4(177.2-494.7)$ & $301.2(169.3-459.9)$ & $349.8(204.7-518.4)$ & $324.5(167.6-522.9)$ & $<0.001$ \\
\hline & Seasonings & $33.3(22.7-56.6)$ & $31.7(21.9-50.8)$ & $33.7(22.9-57.0)$ & $35.0(23.6-63.0)$ & $<0.001$ \\
\hline \multicolumn{7}{|l|}{ Women } \\
\hline & Grains & $215.9(168.8-269.3)$ & $201.0(157.9-248.2)$ & $213.0(166.9-263.1)$ & $251.4(200.9-307.8)$ & $<0.001$ \\
\hline & Potatoes & $20.5(0.0-47.9)$ & $20.6(0.0-46.3)$ & $21.0(0.0-48.5)$ & $20.1(0.0-51.0)$ & 0.86 \\
\hline & Sugars & $2.5(0.4-5.6)$ & $2.8(0.7-5.9)$ & $2.8(0.6-6.2)$ & $1.9(0.0-4.7)$ & $<0.001$ \\
\hline & Pulses & $25.8(1.8-55.9)$ & $25.2(2.6-52.6)$ & $26.4(3.1-57.8)$ & $25.9(0.0-60.8)$ & 0.06 \\
\hline & Sesame and nuts & $0.0(0.0-0.7)$ & $0.0(0.0-1.2)$ & $0.0(0.0-0.8)$ & $0.0(0.0-0.0)$ & $<0.001$ \\
\hline & Vegetables & $151.0(97.4-214.1)$ & $150.3(99.0-208.2)$ & $155.0(99.6-222.0)$ & $148.8(92.6-216.4)$ & 0.005 \\
\hline & Fruits & $49.0(0.0-104.8)$ & $56.7(1.7-107.5)$ & $55.9(0.0-115.1)$ & $12.6(0.0-86.0)$ & $<0.001$ \\
\hline & Mushrooms & $2.8(0.0-15.1)$ & $3.5(0.0-15.0)$ & $3.2(0.0-16.1)$ & $0.0(0.0-14.1)$ & $<0.001$ \\
\hline & Seaweeds & $0.9(0.0-8.2)$ & $1.0(0.0-8.0)$ & $0.9(0.0-9.3)$ & $0.6(0.0-7.6)$ & 0.029 \\
\hline & Fish and shellfish & $34.1(5.9-61.5)$ & $31.8(5.9-57.0)$ & $36.2(7.3-64.2)$ & $36.9(4.4-66.7)$ & $<0.001$ \\
\hline & Meat and poultry & 40.4 (17.9-65.5) & $39.9(18.8-63.5)$ & 39.7 (16.9-64.5) & $42.0(16.6-69.7)$ & 0.10 \\
\hline & Eggs & $18.9(0.4-32.7)$ & $18.8(1.7-31.3)$ & $19.1(0.0-32.6)$ & $18.9(0.0-35.1)$ & 0.80 \\
\hline & Oils & $4.6(1.9-8.1)$ & $4.8(2.2-8.3)$ & $4.6(1.8-8.1)$ & $4.2(1.5-7.9)$ & $<0.001$ \\
\hline & Confectionaries & $0.0(0.0-22.1)$ & $3.5(0.0-22.8)$ & $0.0(0.0-23.7)$ & $0.0(0.0-18.6)$ & $<0.001$ \\
\hline & Beverages & $322.7(178.9-496.3)$ & $300.2(169.5-457.9)$ & $355.5(215.3-526.0)$ & $324.4(163.5-528.7)$ & $<0.001$ \\
\hline & Seasonings & $35.1(23.7-56.2)$ & $33.6(22.8-53.5)$ & $35.4(24.3-56.6)$ & $37.2(24.8-61.1)$ & $<0.001$ \\
\hline
\end{tabular}

${ }^{1}$ Values are medians (IQR). Food groups are expressed as amount per 1000 kcal energy intake. ${ }^{2}$ Milk, milk consumers; Dairy, other dairy consumers; Non-dairy, non-dairy consumers.

${ }^{3}$ The $p$ value shows the result of Kruskal-Wallis tests to compare food intakes between dairy intake groups. 
Table 4. Daily nutrient intakes and prevalence of not meeting DRIs (DG and EAR) among 9987 men according to dairy intake status 1,2,3,4.

\begin{tabular}{|c|c|c|c|c|c|c|c|c|c|}
\hline & \multicolumn{2}{|c|}{ All } & \multicolumn{2}{|c|}{ Milk } & \multicolumn{2}{|c|}{ Dairy } & \multicolumn{2}{|c|}{ Non-Dairy } & \multirow[b]{2}{*}{$p^{5}$} \\
\hline & Intakes & $\begin{array}{c}\text { Not } \\
\text { Meeting } \\
\text { DRIs: \% } \\
\text { (above) }\end{array}$ & Intakes & $\begin{array}{l}\text { Not } \\
\text { Meeting } \\
\text { DRIs: \% } \\
\text { (above) }\end{array}$ & Intakes & $\begin{array}{l}\text { Not } \\
\text { Meeting } \\
\text { DRIs: \% } \\
\text { (above) }\end{array}$ & Intakes & $\begin{array}{l}\text { Not } \\
\text { Meeting } \\
\text { DRIs: \% } \\
\text { (above) }\end{array}$ & \\
\hline Energy, kcal/day & $\begin{array}{c}2062.8 \\
(1720.2-2442.8)\end{array}$ & & $\begin{array}{c}2144.9 \\
(1808.2-2517.6)\end{array}$ & & $\begin{array}{c}2083.8 \\
(1764.4-2447.6)\end{array}$ & & $\begin{array}{c}1945.7 \\
(1580.8-2349.3)\end{array}$ & & \\
\hline \multicolumn{10}{|l|}{ Nutrients with DG } \\
\hline Protein, $\%$ energy & $14.3(12.5-16.3)$ & $\begin{array}{l}36.5 \\
(4.6)\end{array}$ & $14.6(12.8-16.4)$ & $\begin{array}{l}31.4 \\
(4.0)\end{array}$ & $14.4(12.6-16.4)$ & $\begin{array}{l}35.3 \\
(5.0)\end{array}$ & $14.0(11.9-16.2)$ & $\begin{array}{l}42.8 \\
(5.1)\end{array}$ & $<0.001$ \\
\hline Fat, \% energy & $25.4(20.6-30.5)$ & $\begin{array}{c}49.3 \\
(27.1)\end{array}$ & $26.8(22.2-31.3)$ & $\begin{array}{c}46.0 \\
(31.3)\end{array}$ & $25.2(20.4-30.5)$ & $\begin{array}{c}50.0 \\
(27.3)\end{array}$ & $24.0(18.9-29.2)$ & $\begin{array}{c}52.4 \\
(22.3)\end{array}$ & $<0.001$ \\
\hline Saturated fat, \% energy & $6.5(5.0-8.3)$ & 41.8 & $7.3(6.0-9.0)$ & 56.2 & $6.3(4.9-8.0)$ & 38.9 & $5.6(4.1-7.2)$ & 28.0 & $<0.001$ \\
\hline Carbohydrate, \% energy & $59.9(54.3-65.3)$ & $\begin{array}{c}38.5 \\
(26.3)\end{array}$ & $58.5(53.4-63.4)$ & $\begin{array}{c}33.1 \\
(19.0)\end{array}$ & $60.1(54.4-65.1)$ & $\begin{array}{c}38.1 \\
(25.7)\end{array}$ & $61.6(55.5-67.6)$ & $\begin{array}{c}44.7 \\
(34.9)\end{array}$ & $<0.001$ \\
\hline Dietary fibre, $\mathrm{g} / \mathrm{d}$ & $16.8(13.0-21.4)$ & 67.0 & $17.0(13.4-21.5)$ & 65.7 & $17.4(13.5-22.0)$ & 64.9 & $16.1(12.3-20.9)$ & 69.8 & $<0.001$ \\
\hline Sodium (salt-equivalent), g/day & $12.2(9.8-15.2)$ & 89.3 & $11.7(9.5-14.3)$ & 88.4 & $12.2(9.8-15.3)$ & 89.8 & $12.8(10.1-16.1)$ & 89.9 & 0.08 \\
\hline Potassium, mg/day & $2679(2193-3246)$ & 65.4 & $2828(2358-3366)$ & 58.4 & $2725(2243-3305)$ & 63.5 & $2471(2015-3018)$ & 74.4 & $<0.001$ \\
\hline \multicolumn{10}{|l|}{ Nutrients with EAR } \\
\hline Protein, g/d & $87.4(76.1-100.0)$ & 0.9 & $88.2(78.0-99.5)$ & 0.4 & $87.5(76.5-101.0)$ & 0.8 & $86.5(73.2-100.2)$ & 1.7 & $<0.001$ \\
\hline Vitamin $A$, $\mu \mathrm{g}$ RE/day & $470(302-708)$ & 65.1 & $528(357-755)$ & 58.8 & $465(303-700)$ & 65.6 & $409(239-639)$ & 71.7 & $<0.001$ \\
\hline Thiamine, mg/day & $1.00(0.80-1.27)$ & 60.9 & $1.02(0.84-1.27)$ & 59.0 & $1.00(0.78-1.29)$ & 60.2 & $0.98(0.76-1.27)$ & 63.4 & $<0.001$ \\
\hline Riboflavin, mg/day & $1.33(1.06-1.65)$ & 38.5 & $1.46(1.21-1.77)$ & 24.8 & $1.30(1.06-1.60)$ & 39.5 & $1.18(0.93-1.49)$ & 53.0 & $<0.001$ \\
\hline Niacin, NEmg/day & $32.9(27.3-39.3)$ & 0.0 & $32.5(27.5-38.2)$ & 0.0 & $33.5(27.6-40.2)$ & & $32.9(26.8-40.1)$ & 0.1 & 0.29 \\
\hline Vitamin B-6, mg/day & $1.38(1.12-1.69)$ & 32.8 & $1.41(1.15-1.69)$ & 29.5 & $1.39(1.13-1.71)$ & 31.7 & $1.34(1.08-1.67)$ & 37.1 & $<0.001$ \\
\hline Vitamin B-12, $\mu \mathrm{g} /$ day & $5.4(2.9-10.2)$ & 13.6 & $5.4(3.1-9.7)$ & 9.3 & $5.5(2.9-10.6)$ & 14.4 & $5.3(2.6-10.6)$ & 17.9 & $<0.001$ \\
\hline Folate, $\mu \mathrm{g} /$ day & $328(251-421)$ & 11.0 & $332(259-420)$ & 9.0 & $336(262-434)$ & 8.9 & $317(237-412)$ & 14.5 & $<0.001$ \\
\hline Vitamin C, mg/day & $89.8(55.6-140.9)$ & 46.8 & $95.6(60.2-147.3)$ & 43.1 & $97.8(59.6-150.1)$ & 42.1 & $79.6(48.2-125.2)$ & 53.8 & $<0.001$ \\
\hline Calcium, mg/day Magnesium, & $544(390-738)$ & 56.4 & $672(511-850)$ & 37.1 & $551(416-719)$ & 56.7 & $416(312-565)$ & 77.5 & $<0.001$ \\
\hline $\mathrm{mg} /$ day & $296(248-353)$ & 46.1 & $302(256-354)$ & 41.8 & $302(256-360)$ & 43.0 & $284(237-345)$ & 52.9 & $<0.001$ \\
\hline Iron, mg/day & $9.2(7.6-11.0)$ & 8.3 & $9.1(7.5-10.8)$ & 7.6 & $9.3(7.7-11.2)$ & 7.1 & $9.2(7.5-11.2)$ & 10.0 & 0.002 \\
\hline Zinc, mg/day & $10.0(8.8-11.5)$ & 13.6 & $10.2(9.0-11.6)$ & 10.8 & $9.9(8.7-11.4)$ & 14.6 & $9.9(8.6-11.4)$ & 16.0 & $<0.001$ \\
\hline Copper, mg/day & $1.4(1.2-1.6)$ & 0.6 & $1.4(1.2-1.6)$ & 0.4 & $1.4(1.2-1.7)$ & 0.5 & $1.5(1.2-1.7)$ & 0.8 & 0.11 \\
\hline
\end{tabular}

${ }^{1}$ Intakes values are medians (IQR). Nutrients expressed as energy-adjusted values by using the following equation: energy-adjusted intake (unit/day) $=$ observed intake (unit/day) $\times$ Estimated Energy Requirement (EER, kcal/day) / observed energy intake (kcal/day). ${ }^{2}$ Prevalence of not meeting DRIs is percentage of participants whose intake fell outside the range of dietary goals (DG) or below the estimated average requirement (EAR). Each energy-adjusted nutrient intake (unit/day) was compared with each DRI (dietary reference intake) value (unit/day), using the cut-point method. The probability of inadequacy of $>50 \%$ for menstruating women whose bioavailability of iron is $15 \%$ ( $<9.3 \mathrm{mg} /$ day) was considered not meeting EAR for women aged 20-49 years. ${ }^{3}$ All nutrient intakes, except vitamin B12 in men, were significantly different across the dairy intake groups ( $p<0.05 ;$ Kruskal-Wallis test). ${ }^{4}$ Milk, milk consumers; Dairy, other dairy consumers; Non-dairy, non-dairy consumers; RE, retinol equivalent; NE, niacin equivalent. ${ }^{5}$ Difference in the prevalence of not meeting DG and EAR was tested using Cochran-Mantel-Haenszel test adjusting for age categories. 
Table 5. Daily nutrient intakes and prevalence of not meeting DRIs (DG and EAR) among 11,619 women according to dairy intake status $1,2,3,4$.

\begin{tabular}{|c|c|c|c|c|c|c|c|c|c|}
\hline & \multicolumn{2}{|c|}{ All } & \multicolumn{2}{|l|}{ Milk } & \multicolumn{2}{|l|}{ Dairy } & \multicolumn{2}{|c|}{ Non-Dairy } & \multirow[b]{2}{*}{$p^{5}$} \\
\hline & Intakes & $\begin{array}{c}\text { Not } \\
\text { Meeting } \\
\text { DRIs: } \\
\% \text { (above) }\end{array}$ & Intakes & $\begin{array}{c}\text { Not Meeting } \\
\text { DRIs: \%(above) }\end{array}$ & Intakes & $\begin{array}{c}\text { Not } \\
\text { Meeting } \\
\text { DRIs: } \\
\text { \%(above) }\end{array}$ & Intakes & $\begin{array}{c}\text { Not } \\
\text { Meeting } \\
\text { DRIs: } \\
\% \text { (above) }\end{array}$ & \\
\hline Energy, kcal/d & $\begin{array}{c}1654.0 \\
(1386.2-1943.8)\end{array}$ & & $\begin{array}{c}1742.0 \\
(1482.8-2014.8)\end{array}$ & & $\begin{array}{c}1644.1 \\
(1394.2-1927.6)\end{array}$ & & $\begin{array}{c}1515.4 \\
(1235.4-1788.9)\end{array}$ & & - \\
\hline \multicolumn{10}{|l|}{ Nutrients with DG } \\
\hline Protein, $\%$ energy & $15.0(13.1-17.1)$ & $\begin{array}{l}30.7 \\
(7.0)\end{array}$ & $15.2(13.4-17.1)$ & $\begin{array}{l}26.6 \\
(6.0)\end{array}$ & $15.0(13.1-17.2)$ & $\begin{array}{l}31.7 \\
(7.8)\end{array}$ & $14.7(12.6-17.0)$ & $\begin{array}{l}36.6 \\
(7.9)\end{array}$ & $<0.001$ \\
\hline Fat, \% energy & $27.2(22.3-32.3)$ & $\begin{array}{c}51.1 \\
(35.1)\end{array}$ & $28.4(23.8-33.1)$ & $\begin{array}{c}51.0 \\
(40.7)\end{array}$ & $26.8(22.132 .0)$ & $\begin{array}{c}50.4 \\
(33.1)\end{array}$ & $25.4(20.2-30.9)$ & $\begin{array}{l}52.0 \\
(27.7)\end{array}$ & 0.44 \\
\hline Saturated fat, \% energy & $7.1(5.4-9.1)$ & 51.9 & $8.1(6.5-9.9)$ & 67.1 & $6.8(5.1-8.6)$ & 46.0 & $5.8(4.3-7.6)$ & 32.2 & $<0.001$ \\
\hline Carbohydrate, $\%$ energy & $57.3(51.8-63.1)$ & $\begin{array}{c}36.3 \\
(17.9)\end{array}$ & $56.2(50.9-61.4)$ & $\begin{array}{c}33.4 \\
(12.1)\end{array}$ & $57.7(52.1-63.3)$ & $\begin{array}{c}36.2 \\
(18.5)\end{array}$ & $59.4(53.3-65.8)$ & $\begin{array}{c}41.3 \\
(27.3)\end{array}$ & $<0.001$ \\
\hline Dietary fibre, $g /$ day & $15.5(12.0-19.5)$ & 64.8 & $15.6(12.2-19.3)$ & 65.2 & $15.9(12.2-20.0)$ & 62.4 & $15.1(11.6-19.4)$ & 66.4 & 0.05 \\
\hline Sodium (salt-equivalent), g/day & $10.0(7.9-12.4)$ & 85.2 & $9.6(7.8-11.8)$ & 83.8 & $10.2(8.1-12.5)$ & 86.3 & $10.5(8.2-13.2)$ & 86.3 & 0.001 \\
\hline Potassium, mg/day & 2405 (1965-2911) & 60.9 & $2513(2099-2989)$ & 55.4 & 2429 (1989-2944) & 59.5 & $2190(1771-2676)$ & 71.8 & $<0.001$ \\
\hline \multicolumn{10}{|l|}{ Nutrients with EAR } \\
\hline Protein, g/day & $70.6(61.7-80.6)$ & 0.9 & $71.5(62.9-80.6)$ & 0.4 & $70.4(61.7-80.6)$ & 0.7 & $69.1(59.4-80.4)$ & 1.8 & $<0.001$ \\
\hline Vitamin A, $\mu \mathrm{g}$ RE/day & $446(292-651)$ & 55.2 & $485(339-679)$ & 49.7 & $425(282-640)$ & 57.5 & $382(227-607)$ & 62.4 & $<0.001$ \\
\hline Thiamine, mg/day & $0.83(0.67-1.03)$ & 55.8 & $0.84(0.70-1.03)$ & 54.1 & $0.83(0.66-1.04)$ & 55.6 & $0.80(0.63-1.03)$ & 58.8 & $<0.001$ \\
\hline Riboflavin, mg/day & $1.17(0.93-1.44)$ & 28.8 & $1.27(1.06-1.53)$ & 17.3 & $1.14(0.91-1.40)$ & 31.8 & $1.01(0.80-1.29)$ & 45.4 & $<0.001$ \\
\hline Niacin, NEmg/day & $26.3(22.0-31.4)$ & 0.1 & $26.1(22.2-31.0)$ & 0.0 & $26.7(22.3-31.8)$ & & $26.4(21.4-32.1)$ & 0.2 & 0.003 \\
\hline Vitamin B-6, mg/day & $1.15(0.92-1.41)$ & 33.5 & $1.16(0.94-1.41)$ & 31.5 & $1.16(0.93-1.43)$ & 32.4 & $1.12(0.88-1.39)$ & 37.7 & $<0.001$ \\
\hline Vitamin B-12, $\mu \mathrm{g} /$ day & $4.2(2.2-8.2)$ & 21.3 & $4.3(2.5-8.0)$ & 16.3 & $4.3(2.2-8.3)$ & 22.3 & $4.0(1.8-8.6)$ & 28.7 & $<0.001$ \\
\hline Folate, $\mu \mathrm{g} /$ day & $299(230-382)$ & 15.4 & $297(233-375)$ & 14.3 & $306(236-395)$ & 13.6 & $293(219-382)$ & 19.0 & $<0.001$ \\
\hline Vitamin C, mg/day & $92.2(57.9-143.1)$ & 45.5 & $93.5(60.1-143.4)$ & 44.1 & $\begin{array}{c}100.1 \\
(62.3-151.7)\end{array}$ & 42.0 & $83.3(48.8-132.9)$ & 51.4 & $<0.001$ \\
\hline Calcium, mg/day & $521(377-683)$ & 52.4 & $618(484-774)$ & 34.1 & $501(387-646)$ & 56.4 & $373(280-503)$ & 79.3 & $<0.001$ \\
\hline Magnesium, mg/day & $254(212-302)$ & 38.1 & $258(217-304)$ & 34.9 & $258(216-309)$ & 36.5 & $242(199-292)$ & 45.0 & $<0.001$ \\
\hline Iron, mg/day & $7.9(6.5-9.6)$ & 29.1 & $7.7(6.4-9.3)$ & 30.6 & $8.2(6.6-9.8)$ & 25.0 & $8.1(6.6-9.9)$ & 30.6 & $<0.001$ \\
\hline Zinc, mg/day & $7.9(7.0-9.0)$ & 7.8 & $8.1(7.2-9.1)$ & 5.9 & $7.9(6.9-8.9)$ & 8.2 & $7.8(6.8-8.9)$ & 10.7 & $<0.001$ \\
\hline Copper, mg/day & $1.2(1.0-1.4)$ & 0.6 & $1.1(1.0-1.3)$ & 0.6 & $1.2(1.0-1.4)$ & 0.6 & $1.2(1.0-1.4)$ & 0.7 & 0.95 \\
\hline
\end{tabular}

${ }^{1}$ Intakes values are medians (IQR). Nutrients expressed as energy-adjusted values by using the following equation: energy-adjusted intake (unit/day) $=$ observed intake (unit/day) $\times$ Estimated Energy Requirement (EER, kcal/day)/observed energy intake (kcal/day). ${ }^{2}$ Prevalence of not meeting DRIs is percentage of participants whose intake fell outside the range of DG or below the EAR. Each energy-adjusted nutrient intake (unit/d) was compared with each DRI value (unit/day), using the cut-point method. The probability of inadequacy of $>50 \%$ for menstruating women whose bioavailability of iron is $15 \%(<9.3 \mathrm{mg} /$ day $)$ was considered not meeting EAR for women aged $20-49$ years. ${ }^{3}$ All nutrient intakes, except vitamin B12 in men were significantly different across the dairy intake groups ( $p<0.05$; Kruskal-Wallis test). ${ }^{4}$ Milk, milk consumers; Dairy, other dairy consumers; Non-dairy, non-dairy consumers; RE, retinol equivalent; NE, niacin equivalent. ${ }^{5}$ Difference in the prevalence of not meeting DG and EAR was tested using Cochran-Mantel-Haenszel test adjusting for age categories. 
Table 6. Number of nutrients with not meeting DG and EAR among 9987 men and 11,619 women according to dairy intake status $1,2$.

\begin{tabular}{|c|c|c|c|c|c|}
\hline & All & Milk & Dairy & Non-Dairy & $p^{3}$ \\
\hline Men & & & & & \\
\hline Number of nutrients with not meeting DG & $3.9 \pm 1.5$ & $3.8 \pm 1.5$ & $3.8 \pm 1.5$ & $4.0 \pm 1.5$ & $<0.001$ \\
\hline $\begin{array}{c}\text { Number of nutrients with not meeting EAR } \\
\text { Women }\end{array}$ & $4.0 \pm 2.5$ & $3.3 \pm 2.4$ & $3.9 \pm 2.5$ & $4.7 \pm 2.5$ & $<0.001$ \\
\hline Number of nutrients with not meeting DG & $3.8 \pm 1.5$ & $3.8 \pm 1.5$ & $3.7 \pm 1.5$ & $3.9 \pm 1.5$ & 0.08 \\
\hline Number of nutrients with not meeting EAR & $3.8 \pm 2.7$ & $3.3 \pm 2.6$ & $3.9 \pm 2.6$ & $4.7 \pm 2.7$ & $<0.001$ \\
\hline
\end{tabular}

${ }^{1}$ Milk, milk consumers; Dairy, other dairy consumers; Non-dairy, non-dairy consumers. ${ }^{2}$ Values are mean \pm SD. ${ }^{3}$ Significance of difference between groups was compared using ANCOVA adjusting for age categories. 


\section{Discussion}

In the present study, we compared the nutrient intake adequacy of individuals who reported consuming milk or other dairy products to that of those who reported not consuming any dairy products using a 1-day dietary record. In a comparison of the number of nutrients not meeting DRIs, dairy consumers (both milk consumers and other dairy consumers) were more likely to have adequate nutrient intake than non-dairy consumers. However, for saturated fat, dairy consumers had higher intake (above the DG level) than non-dairy consumers. To the best of our knowledge, this is the first report that studied nutritional adequacy according to milk and dairy products intake among Japanese adults. It is important to examine this issue in a population with lower dairy intake to understand the influence of dairy products intake on nutritional intake in people with different characteristics.

Even among the dairy consumers in the current study, the mean daily intake of dairy products was approximately $160 \mathrm{~g}$ in milk consumers and $70 \mathrm{~g}$ in other dairy consumers; this was the same in both men and women. In an Irish study, the mean dairy product intake in dairy consumers was reported as $291 \mathrm{~g}$ [14], and the average liquid milk intake in the US was reported to be around $180 \mathrm{~mL}$ (186 g, using $103.2 \mathrm{~g} / 100 \mathrm{~mL}$ for conversion factor [32]) [33], while in Japan the reported amount is about $60 \mathrm{~mL}(62 \mathrm{~g})$ [18]. In the current study, dairy consumers had less intake of "grains" and "seasoning" than non-dairy consumers. In addition, milk consumers had less intakes of "fish and shellfish" than non-dairy consumers. A previous study has indicated that dairy products are consumed with bread rather than rice or noodles as dietary staples among Japanese population [34]. Together with the present findings, this suggests that a non-dairy diet may be a result of rice-based meals with greater amounts of fish, which is regarded as a traditional Japanese diet. In turn, this might also suggest that a diet with dairy products is a Westernised Japanese diet. Another Japanese study using NHNS data described that a dietary pattern mainly consisting of bread and dairy products has been increasing in Japanese adults [35], which may point to a shift in the Japanese diet, despite much lower dairy consumption compared to that in Western countries.

The association between dairy products intake and nutritional intake has been examined in several studies, mainly in Western countries. For example, a diet modelling study showed that increasing dairy food consumption to recommended amounts could improve the intake of essential vitamins and minerals that were inadequately consumed [36]. Similar to our results, a US study reported that consumption of milk (plain or flavoured) was associated with better macro- and micronutrients intake among children and adolescents [11], and other studies have shown similar results $[6,10]$. In the present study, the greatest difference in inadequate intake of nutrients between milk consumers and non-dairy consumers was found to be for calcium, which could be greatly responsible for the total number difference of those not meeting EAR. The contribution of dairy intake to calcium intake has been reported using nutrient profiling methods [37]. Only $28 \%$ of the calcium intake of a Japanese adult is received from dairy products. Other foods, especially vegetables or pulses, also contribute to calcium intake in the Japanese diet [18]. Although in this study the intake of "vegetables" was higher in dairy consuming men, a similar pattern was not observed in the intakes of "pulses" and "vegetables" in dairy consuming women. Therefore, dairy intake itself might be responsible for the relatively adequate calcium intake in this study. However, there still was a considerable number of non-dairy consumers (approximately 20\%) who achieved adequate calcium intake without dairy products. This is not consistent with previous Western studies which suggested that milk and dairy intake particularly influence calcium intake because only those who consumed milk had an average dietary calcium intake close to their recommended levels $[10,11,17,36]$. Further studies are needed to explore the factors contributing to adequate calcium intake in the Japanese population for future public health strategies. On another note, more fruit and mushrooms were consumed by dairy consumers in this study. This result is also similar to that described in a previous study, which identified a combination of dairy products and fruit as one of the typical meals among Japanese people [34]. These food intakes among dairy consumers could also explain the better intake of certain nutrients, such as vitamin $C$ and dietary fibre, because milk and many other dairy products lack such nutrients [22]. Our finding also 
suggests that older people are more likely to consume dairy products, which is consistent with the annual reports of NHNS showing higher dairy products intake among older people than younger people [18]. The NHNS has shown that older people are more likely to have better dietary intake, such as more fruit and vegetables [18]. Further assessments are needed to investigate the dietary intake patterns according to the age difference, and in relation to dairy products intake.

Despite adequate nutritional intake observed among dairy consumers for EAR, the difference in the number of those not meeting DG was small, even though statistically significant differences were observed. The DG values were set to achieve better nutritional intake from the standpoint of prevention of life-style related diseases such as diabetes, hypertension, and dyslipidaemia [25]. Among nutrients with DG, the difference in the prevalence of not meeting DG was observed for several nutrients such as potassium and protein according to dairy intake status, with more favourable intake in dairy consumers. However, there was a higher prevalence of excess saturated fat intake in both male and female dairy consumers. These could substantially explain the small difference in the number of not meeting DG compared to not meeting EAR. Regarding excess saturated fat intake, similar results have been observed in previous studies $[10,11,13,14,17]$. In NHNS 2016, in the same participants used as the sample for this study, $17 \%$ of saturated fat came from dairy products [18]. Dairy product intake has been identified in meals with bread in Japanese adults [34] and another Japanese study reported that breakfast bread intake was associated with higher saturated fat intake in young women [38]. From these findings, not only dairy foods, but the combination with bread may play an important role in Japanese saturated fat intake. According to a Japanese dietary guideline (Japanese Food Guide Spinning Top), daily intake of one serving of milk ( $200 \mathrm{~mL} ; 206 \mathrm{~g})$ or its equivalent is recommended [39], which contains a saturated fat level of $4.8 \mathrm{~g}$ (full-fat milk) [22]. This milk amount exceeds the median milk intake of the participants of the current study, even that of milk consumers. A Japanese study has attempted to design optimal dietary intake to achieve a full set of nutritional recommendations in the Japanese DRIs, suggesting a reduction in consuming full-fat dairy and increasing the intake of low-fat dairy products [40]. This might partly reflect the contribution of full-fat dairy to saturated fat intake among Japanese adults. In fact, most of the milk consumed in this study was full-fat milk, with the mean low-fat milk consumption being $21.1 \mathrm{~g}$ and $20.6 \mathrm{~g}$ in men and women, respectively (data not shown). Therefore, to develop an appropriate public health strategy, further studies using diet modelling methods are needed to set an adequate dairy intake in the Japanese diet. In contrast, a US study has recently reported that long-term intake of dairy fatty acids was not associated with all-cause mortality and cardiovascular disease mortality among older adults [41]. Furthermore, there has been a report showing a negative association between risk of cardiovascular diseases and dairy saturated fat intake [42]. The effectiveness of dairy product intake as a source of saturated fat intake also needs to be further examined.

Several limitations of this study need to be mentioned. First, the study samples were randomly selected from nationally representative households in Japan; however, only $44.4 \%$ of selected households participated in the survey. Furthermore, the individual-level response rate within the household is unknown. Additionally, the dietary survey was conducted on intentionally selected single weekdays in only two months from October to December. This might induce some bias in the estimation of average intake in Japanese adults. Second, a dietary intake derived from a 1-day weighed dietary record is unlikely to represent the usual intake of individual respondents. Therefore, day-to-day variability in the dietary intake of individuals might have influenced the findings. Moreover, while the validity of the household-based dietary record used for this survey has been examined among young women, the true utility of this methodology for assessing daily dietary intake among men or people in other age groups is unknown. Furthermore, measurement error could be caused by misreporting of self-reported food intake. Finally, we classified the participants according to their milk or dairy consumption only, regardless of the amount consumed. Further investigation is needed to estimate the adequate number of dairy products. Additionally, it should be noted that diet quality is defined by the totality of foods consumed rather than by the presence or absence of a single food [43-45]. Although 
nutrition intake was better among dairy consumers in part, public health messages should focus on promoting healthier food choices.

\section{Conclusions}

In conclusion, despite lower dairy intake compared to Western populations, dairy consumers (milk consumers and other dairy consumers) had more adequate nutritional intake, particularly for calcium, than non-dairy consumers. However, a diet with dairy products was more likely to associate with excess saturated fat intake. Although dairy intake might be a sign of healthier dietary behaviour in Japanese adults, further investigation is needed to determine dairy intake and its influence on overall dietary intake among the Japanese population.

Author Contributions: A.S. and H.T. designed and conducted research; A.S. performed statistical analysis, interpreted the data and wrote the first draft; E.O., I.T. and M.M. took part in the interpretation of the data and provided critical revisions of the manuscript for important intellectual content; H.T. had primary responsibility for final content; and all authors have read and approved the final manuscript.

Funding: This study was supported by the Health Japan 21 (the second term) Analysis and Assessment Project, Ministry of Health, Labour, and Welfare. Ministry of Health, Labour, and Welfare had no role in the design, analysis or writing of this article.

Conflicts of Interest: The authors declare no conflict of interest.

\section{References}

1. Ranganathan, R.; Nicklas, T.A.; Yang, S.J.; Berenson, G.S. The nutritional impact of dairy product consumption on dietary intakes of adults (1995-1996): The Bogalusa Heart Study. J. Am. Diet. Assoc. 2005, 105, 1391-1400. [CrossRef] [PubMed]

2. Drewnowski, A.; Fulgoni, V. Nutrient profiling of foods: Creating a nutrient-rich food index. Nutr. Rev. 2008, 66, 23-39. [CrossRef] [PubMed]

3. Lamarche, B. Review of the effect of dairy products on non-lipid risk factors for cardiovascular disease. J. Am. Coll. Nutr. 2008, 27, 741S-746S. [CrossRef] [PubMed]

4. Malik, V.S.; Sun, Q.; van Dam, R.M.; Rimm, E.B.; Willett, W.C.; Rosner, B.; Hu, F.B. Adolescent dairy product consumption and risk of type 2 diabetes in middle-aged women. Am. J. Clin. Nutr. 2011, 94, 854-861. [CrossRef]

5. Elwood, P.C.; Pickering, J.E.; Ian Givens, D.; Gallacher, J.E. The consumption of milk and dairy foods and the incidence of vascular disease and diabetes: An overview of the evidence. Lipids 2010, 45, 925-939. [CrossRef]

6. Tremblay, A.; Gilbert, J.A. Milk products, insulin resistance syndrome and type 2 diabetes. J. Am. Coll. Nutr. 2009, 28, 91S-102S. [CrossRef]

7. Heaney, R.P. Dairy and bone health. J. Am. Coll. Nutr. 2009, 28, 82S-90S. [CrossRef]

8. Rice, B.H.; Quann, E.E.; Miller, G.D. Meeting and exceeding dairy recommendations: Effects of dairy consumption on nutrient intakes and risk of chronic disease. Nutr. Rev. 2013, 71, 209-223. [CrossRef]

9. Talaei, M.; Pan, A.; Yuan, J.-M.; Koh, W.-P. Dairy Food Intake Is Inversely Associated with Risk of Hypertension: The Singapore Chinese Health Study. J. Nutr. 2017, 147, 235-241. [CrossRef]

10. Fayet, F.; Ridges, L.A.; Wright, J.K.; Petocz, P. Australian children who drink milk (plain or flavored) have higher milk and micronutrient intakes but similar body mass index to those who do not drink milk. Nutr. Res. 2013, 33, 95-102. [CrossRef]

11. Murphy, M.M.; Douglass, J.S.; Johnson, R.K.; Spence, L.A. Drinking flavored or plain milk is positively associated with nutrient intake and is not associated with adverse effects on weight status in US children and adolescents. J. Am. Diet. Assoc. 2008, 108, 631-639. [CrossRef] [PubMed]

12. Ballew, C.; Kuester, S.; Gillespie, C. Beverage choices affect adequacy of children's nutrient intakes. Arch. Pediatrics Adolesc. Med. 2000, 154, 1148-1152. [CrossRef] [PubMed]

13. Keast, D.R.; Hill Gallant, K.M.; Albertson, A.M.; Gugger, C.K.; Holschuh, N.M. Associations between yogurt, dairy, calcium, and vitamin D Intake and Obesity among U.S. children aged 8-18 years: NHANES, 2005-2008. Nutrients 2015, 7, 1577-1593. [CrossRef] [PubMed] 
14. Feeney, E.L.; Nugent, A.P.; Mc Nulty, B.; Walton, J.; Flynn, A.; Gibney, E.R. An overview of the contribution of dairy and cheese intakes to nutrient intakes in the Irish diet: Results from the National Adult Nutrition Survey. Br. J. Nutr. 2015, 115, 709-717. [CrossRef] [PubMed]

15. Wang, H.; Livingston, K.A.; Fox, C.S.; Meigs, J.B.; Jacques, P.F. Yogurt consumption is associated with better diet quality and metabolic profile in American men and women. Nutr. Res. 2013, 33, 18-26. [CrossRef] [PubMed]

16. Bowman, S.A. Beverage choices of young females: Changes and impact on nutrient intakes. J. Am. Diet. Assoc. 2002, 102, 1234-1239. [CrossRef]

17. Weaver, C.M. Role of dairy beverages in the diet. Physiol. Behav. 2010, 100, 63-66. [CrossRef]

18. Ministry of Health Labour and Welfare The National Health and Nutrition Survey in Japan. 2016. Available online: http://www.mhlw.go.jp/bunya/kenkou/eiyou/h28-houkoku.html (accessed on 2 February 2019).

19. FAO. Milk and Dairy Products in Human Nutrition; FAO: Rome, Italy, 2013; ISBN 9789251078631.

20. Takimoto, H.; Mitsuishi, C.; Kato, N. Attitudes toward pregnancy related changes and self-judged dieting behavior. Asia Pac. J. Clin. Nutr. 2011, 20, 212-219.

21. Takimoto, H.; Yoshiike, N.; Katagiri, A.; Ishida, H.; Abe, S. Nutritional status of pregnant and lactating women in Japan: A comparison with non-pregnant/non-lactating controls in the National Nutrition Survey. J. Obstet. Gynaecol. Res. 2003, 29, 96-103. [CrossRef]

22. The Council for Science and Technology Ministry of Education Culture Sports and Technology. Standard Tables of Food Composition in Japan 2010; Official Gazette Co-operation: Tokyo, Japan, 2010; ISBN 978-4-915392-87-0.

23. Iwaoka, F.; Yoshiike, N.; Date, C.; Shimada, T.; Tanaka, H. A validation study on a method to estimate nutrient intake by family members through a household-based food-weighing survey. J. Nutr. Sci. Vitaminol. 2001, 47, 222-227. [CrossRef]

24. Murakami, K.; Livingstone, M.B.E.; Okubo, H.; Sasaki, S. Prevalence and characteristics of misreporting of energy intake in Japanese adults: The 2012 National Health and Nutrition Survey. Asia Pac. J. Clin. Nutr. 2018, 27, 441-450. [PubMed]

25. Ministry of Health Labour and Welfare. Dietary Reference Intakes for Japanese, 2015; Daiichi Shuppan Publishing Co., Ltd.: Toyko, Japan, 2014.

26. Kohri, T.; Kaba, N.; Itoh, T.; Sasaki, S. Effects of the National School Lunch Program on Bone Growth in Japanese Elementary School Children. J. Nutr. Sci. Vitaminol. (Tokyo) 2016, 62, 303-309. [CrossRef] [PubMed]

27. Okubo, H.; Sasaki, S.; Murakami, K.; Takahashi, Y. Freshmen in Dietetic Course Study II Group Nutritional adequacy of four dietary patterns defined by cluster analysis in Japanese women aged 18-20 years. Asia Pac. J. Clin. Nutr. 2010, 19, 555-563.

28. Kobayashi, S.; Asakura, K.; Suga, H.; Sasaki, S. Living status and frequency of eating out-of-home foods in relation to nutritional adequacy in 4017 Japanese female dietetic students aged 18-20 years: A multicenter cross-sectional study. J. Epidemiol. 2017, 27, 287-293. [CrossRef] [PubMed]

29. FAO/WHO. Requirements of Vitamin A, Iron, Folate and Vitamin B12. Report of a Joint FAO/WHO Expert Consultation; FAO: Roma, Italy, 1988.

30. Institute of Medicine Food and Nutrition Board. Dietary Reference Intakes: Applications in Dietary Assessment; National Academies Press: Washington, DC, USA, 2000; ISBN 0309073111.

31. WHO/FAO. Guidelines on Food Fortification with Micronutrients; World Health Organization and Food and Agriculture Organization of the United Nations: Geneva, Switzerland, 2006; ISBN 9241594012.

32. The Council for Science and Technology Ministry of Education Science Sports and Culture. Standard Tables of Food Composition in JAPAN, 2015, 7th ed.; Official Gazette Co-operation: Tokyo, Japan, 2015.

33. Sebastian, R.S.; Goldman, J.D.; Enns, C.W.; LaComb, R. Fluid Milk Consumption in the United States. 2010; Volume 3. Available online: https:/www.ars.usda.gov/ARSUserFiles/80400530/pdf/DBrief/3_milk_ consumption_0506.pdf (accessed on 29 September 2019).

34. Murakami, K.; Livingstone, M.B.E.; Sasaki, S. Establishment of a meal coding system for the characterization of meal-based dietary patterns in Japan. J. Nutr. 2017, 147, 254896. [CrossRef] [PubMed]

35. Murakami, K.; Livingstone, M.B.E.; Sasaki, S. Thirteen-year trends in dietary patterns among Japanese adults in the National Health and Nutrition Survey 2003-2015: Continuous Westernization of the Japanese diet. Nutrients 2018, 10, 994. [CrossRef] [PubMed] 
36. Quann, E.E.; Fulgoni, V.L.; Auestad, N. Consuming the daily recommended amounts of dairy products would reduce the prevalence of inadequate micronutrient intakes in the United States: Diet modeling study based on NHANES 2007-2010. Nutr. J. 2015, 14, 90. [CrossRef]

37. Trichterborn, J.; Harzer, G.; Kunz, C. Nutrient profiling and food label claims: Evaluation of dairy products in three major European countries. Eur. J. Clin. Nutr. 2011, 65, 1032-1038. [CrossRef]

38. Sasaki, S.; Shimoda, T.; Katagiri, A.; Tsuji, T.; Amano, K. Eating frequency of rice vs. bread at breakfast and nutrient and food-group intake among Japanese female college students. J. Community Nutr. 2002, 4, 83-89.

39. Yoshiike, N.; Hayashi, F.; Takemi, Y.; Mizoguchi, K.; Seino, F. A new food guide in Japan: The Japanese Food Guide Spinning Top. Nutr. Rev. 2007, 65, 149-154. [CrossRef]

40. Okubo, H.; Sasaki, S.; Murakami, K.; Yokoyama, T.; Hirota, N.; Notsu, A.; Fukui, M.; Date, C. Designing optimal food intake patterns to achieve nutritional goals for Japanese adults through the use of linear programming optimization models. Nutr. J. 2015, 14, 57. [CrossRef] [PubMed]

41. de Oliveira Otto, M.C.; Lemaitre, R.N.; Song, X.; King, I.B.; Siscovick, D.S.; Mozaffarian, D. Serial measures of circulating biomarkers of dairy fat and total and cause-specific mortality in older adults: The Cardiovascular Health Study. Am. J. Clin. Nutr. 2018. [CrossRef] [PubMed]

42. De Oliveira Otto, M.C.; Mozaffarian, D.; Kromhout, D.; Bertoni, A.G.; Sibley, C.T.; Jacobs, D.R.; Nettleton, J.A. Dietary intake of saturated fat by food source and incident cardiovascular disease: The Multi-Ethnic Study of Atherosclerosis. Am. J. Clin. Nutr. 2012, 96, 397-404. [CrossRef] [PubMed]

43. Jacobs, D.R.; Gross, M.D.; Tapsell, L.C. Food synergy: An operational concept for understanding nutrition. Am. J. Clin. Nutr. 2009, 89, 1543S-1548S. [CrossRef]

44. Jacobs, D.R.; Tapsell, L.C. What an anticardiovascular diet should be in 2015. Curr. Opin. Lipidol. 2015, 26, 270-275. [CrossRef]

45. Ocké, M.C. Evaluation of methodologies for assessing the overall diet: Dietary quality scores and dietary pattern analysis. Proc. Nutr. Soc. 2013, 72, 191-199. [CrossRef]

(C) 2019 by the authors. Licensee MDPI, Basel, Switzerland. This article is an open access article distributed under the terms and conditions of the Creative Commons Attribution (CC BY) license (http://creativecommons.org/licenses/by/4.0/). 